\title{
Red face and reduced plasma volume
}

\author{
SYLVIA W. DAVIES, EVELINE GLYNNE-JONES, AND E. PATRICIA LEWIS ${ }^{1}$ \\ From the Area Department of Pathology, Exeter
}

SYNOPSIS Twenty-five patients who were suspected clinically of having either polycythaemia rubra vera or secondary polycythaemia had no haematological abnormalities apart from a reduction in the plasma volume. Twenty-one were hypertensive. The plasma volume was lowest in those who were receiving treatment with diuretic agents, antihypertensive drugs, or steroid therapy. These cases demonstrate the need for blood volume studies in patients with high values for the blood haemoglobin and the packed cell volume in order to establish a differential diagnosis from myeloproliferative disorder or secondary polycythaemia.

\section{Patients}

Twenty-five patients were referred for investigation because they had been suspected clinically of having either polycythaemia rubra vera or secondary polycythaemia. They looked plethoric and random estimations of the blood haemoglobin and the packed cell volume had shown high normal or higher than normal values.

\section{Investigations}

The patients were examined to exclude enlargement of the spleen. The blood pressure was measured and details were obtained of any treatment that they were receiving.

Haematological investigations included measurement of the blood haemoglobin, the packed cell volume, platelet and reticulocyte counts, with total and differential white cell counts. The bone marrow was examined. Blood volume studies were carried out using sodium chromate $\left({ }^{51} \mathrm{Cr}\right)$ to label the red cells and ${ }^{125} \mathrm{I}$ conjugated with human serum albumin to measure the plasma volume. Results were compared with the range of normal values provided by Dacie and Lewis (1968) and by Lewis (1973). An additional assessment of individual values for the plasma volume and the red cell volume was made by reference to the nomograms contained in Documenta Geigy (1970).

\section{Results}

At the time when the investigations were made the values for the blood haemoglobin and the packed

${ }^{1}$ Now at Torbay Hospital

Received for publication 9 November 1973. cell volume were not always the highest that had been recorded for the particular patient. Reticulocyte and platelet counts were always within normal limits although some patients had an increase in the total white cell count; in such cases it was possible to elicit a history of fairly recent respiratory infection. No abnormalities were seen in stained blood films and in no case did the bone marrow show any evidence of myeloproliferative disorder or erythropoietic predominance.

In all 25 patients the plasma volume was at or below the lower limits of normal. The red cell volume was consistently within normal limits.

RELATIONSHIP TO BLOOD PRESSURE, TREATMENT, AND CLINICAL CONDITION According to the results (see table) that were obtained the patients were divided into three main groups: normotensive, untreated patients; hypertensive, untreated patients; and hypertensive patients receiving various forms of treatment.

\section{Normotensive, untreated paticnts}

Four patients were normotensive with a diastolic blood pressure of less than $90 \mathrm{mmHg}$. None was receiving any treatment. Apart from symptoms of anxiety none had any definite clinical abnormality.

\section{Hypertensive, untreated patients}

Ten patients had a diastolic blood pressure of $90 \mathrm{mmHg}$ or over; they were not receiving any treatment for hypertension at the time of investigation. Four had hypertension without any other evidence of disease. The remaining six patients in this group all had some associated clinical condition. One had been diagnosed on radiological evidence as suffering from carcinoma of the bronchus and he had symp- 


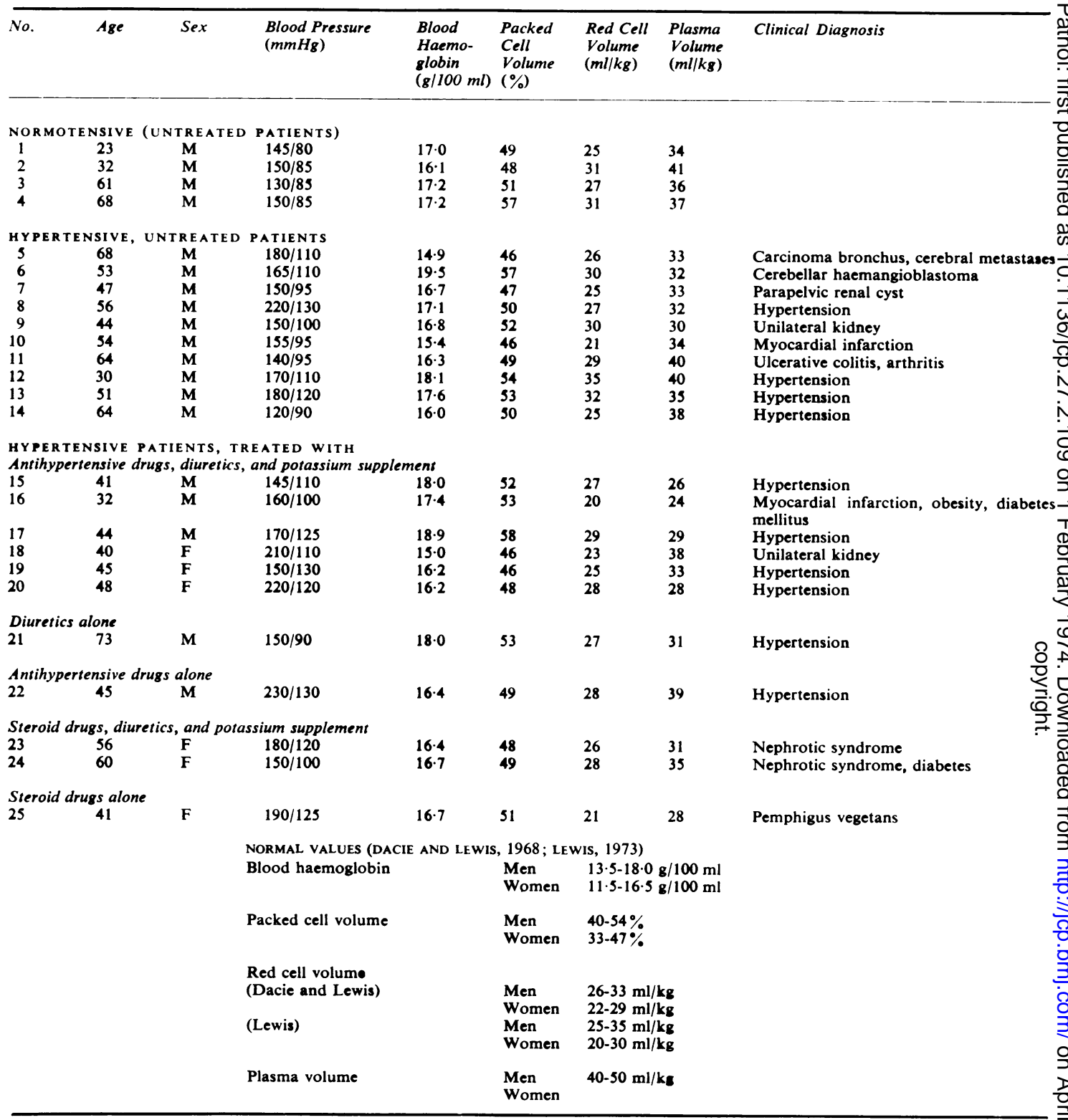

Table Haematological and clinical data for 25 patients with reduced plasma volume

toms of cerebral metastases; no postmortem confirmation was made. Another had a cerebellar haemangioblastoma which was diagnosed by biopsy of the tumour.

\section{Hypertensive patients receiving various forms of treatment}

Eleven patients were included in this group. Six were being treated with antihypertensive drugs, diuretic therapy, and potassium supplement. Of $\stackrel{N}{\sim}$ these, five had uncomplicated hypertension. One had ${ }^{\mathrm{\omega}}$ a single kidney; another had had a myocardial infarction, he was also obese and a mild diabetic.

A single patient was receiving diuretic therapy alone and another was being treated with antihypertensive drugs only. Two patients were receiving steroid therapy with diuretic agents and potassium $\frac{\vec{\Phi}}{\mathbb{D}}$ supplement, one for diabetic nephropathy, the other $\stackrel{\mathbb{D}}{\mathbb{D}}$ 
for nephrotic syndrome due to low-grade proliferative glomerulonephritis. Finally, one hypertensive patient with pemphigus vegetans was receiving steroid therapy alone.

The 25 patients who have been described form a particular, though heterologous group selected from a total of 57 patients who were examined over a period of three years. All of them were suspected clinically of having either polycythaemia rubra vera or secondary polycythaemia. Two were haematologically normal with a normal plasma volume. The remaining 30 patients had increased values for the red cell volume. Fifteen had polycythaemia rubra vera which was confirmed by enlargement of the spleen and evidence of abnormal haemopoiesis in the bone marrow. The rest had secondary polycythaemia which was due to hypoxia or associated with renal disease; in several the erythropoietin level in the plasma was increased.

Although the 25 patients who are the subject of this paper looked plethoric with high values for the blood haemoglobin and the packed cell volume, there was no increase in the red cell volume above normal. The feature common to all was a decrease in the plasma volume which accounted both for their plethoric appearance and for their haemoconcentration.

\section{Discussion}

Numerous terms have been applied to the state of haemoconcentration due to reduced plasma volume which has been described in both normotensive and hypertensive patients. These include 'polycythaemia hypertonica' (Geisböck, 1905); relative polycythaemia: the polycythaemia of stress (Lawrence and Berlin, 1952); pseudo-polycythaemia (Kaung and Peterson, 1962); benign polycythaemia (Russell and Conley, 1964); Geisböck's syndrome (Hall, 1965); and spurious (relative) polycythaemia, which the authors entitled 'a non-existent disease' (Brown, Gilbert, Krauss, and Wasserman, 1971).

Reduction in the plasma volume with normal values for the red cell volume has been described in both normotensive and hypertensive subjects with plethoric appearance. In our series, 21 out of 25 were hypertensive. The condition is more common in association with hypertension but not consistently so (Brown et al, 1971; Bianchi, Campolo, Vegeto, Pietra, and Piazza, 1970). Lawrence and Berlin described 18 patients with reduced plasma volume, only nine of whom were hyprrtensive although nine out of 10 patients investigated by Kuang and Peterson had hypertension. Some confusion has arisen because some series include patients with an increase in the red cell volume (Russell and Conley, 1964; Hall, 1965). In addition any comparison of results between different workers is made difficult because of the number of methods that have been used to measure the plasma volume.

Of the 21 patients in our series 10 were not receiving any treatment for hypertension; 11 were receiving various forms of therapy. The mean plasma volume of the untreated patients $(34.7 \pm 3.0 \mathrm{ml} / \mathrm{kg})$ was lower than the normal range $(40-50 \mathrm{ml} / \mathrm{kg})$ and the mean plasma volume of the treated patients $(31 \cdot 1 \pm 4.0 \mathrm{~m} / \mathrm{kg} ; \mathrm{P}<0 \cdot 1)$ was lower still. Although the literature contains references to high values for the blood haemoglobin and the packed cell volume in patients with hypertension some, including the original paper by Gaisböck, lack blood volume studies (Hilden, Leth, and Hilden, 1968). Investigations that were supported by blood volume studies were made by Tibblin, Bergentz, Bjure, and Wilhemsen (1966) and by Julius, Pascual, Reilly, and London (1971). Both these groups of workers showed that the packed cell volume was higher and the plasma volume lower in hypertensive subjects compared with normal controls.

The total body fluid and the plasma volume of hyp rrtensive patients is reduced following treatment with chlorthiazide (Wilson and Freis, 1959; Conway and Lauwers, 1960; Frohlich, Schnaper, Wilson, and Freis, 1960; and Leth, 1970). Thus it would seem that a red face with reduction in plasma volume is more likely in patients who are treated with diuretic agents.

A previous report describes a case of reduced plasma volume due to excessive alcohol consumption (Smith and Lucie, 1973) and suggests this might be a cause of 'stress erythrocytosis'. However, in our series only one patient had a history of considerable alcohol consumption.

Included in our untreated group were two patients with brain tumours both of whom had a reduced plasma volume without any increase in the red cell volume. This is of interest, since a previous report indicated that such patients may have secondary polycythaemia (Waldmann, Levin, and Baldwin, 1961).

It could be argued that some of our patients (nos. 2, 11, and 12) are haematologically normal and this might suggest that the lower limit of the normal plasma volume is set too high. However, the expected values for the plasma volume (Documenta Geigy, 1970) for these patients were considerably higher.

\section{Conclusion}

A number of patients who look plethoric and have high values for the blood haemoglobin and the packed cell volume show no haematological abnormalities 
apart from a reduction in the plasma volume. The condition is found in both normotensive and hypertensive subjects but it is more commonly associated with hypertension. Treatment with diuretic agents induces a greater decrease in the plasma volume.

Various descriptive terms have been applied to the condition but a more precise definition is needed to exclude the clinical and haematological implication of the word 'polycythaemia'. Whatever name is given to the condition full clinical and haematological investigations are essential in order to provide a differential diagnosis from polycythaemia rubra vera or secondary polycythaemia.

We should like to thank our clinical colleagues in the Exeter clinical area and at the North Devon Infirmary, Barnstaple, for the opportunity to investigate patients under their care. In particular we should like to express our appreciation to $\mathrm{Dr}$ J. O. P. Edgcumbe and Dr R. Sokol for their support and help with the interpretation of bone marrow examination.

The work is supported by a research grant from the South Western Regional Hospital Board.

\section{References}

Bianchi, G., Campolo, L., Vegeto, A., Pietra, V., and Piazza, U. (1970). The value of plasma renin concentration per se, and in relation to plasma and extracellular fluid volume in diagnosis and prognosis of human renovascular hypertension. Clin. Sci., 39, 559-576.

Brown, S. M., Gilbert, H. S., Krauss, S., and Wasserman, L. R. (1971). Spurious (relative) polycythemia: a non-existent disease. Amer. J. Med., 50, 200-207.
Conway, J., and Lauwers, P. (1960). Hemodynamic and hypotensive effects of long-term therapy with chlorothiazide. Circulation 21, 21-27.

Dacie, J. V., and Lewis, S. M. (1968). Practical Haematology, 4th ed.은 pp. 12-13. Churchill, London.

Documenta Geigy (1970). Scientific Tables, 7th edition, p. $556 \overrightarrow{\vec{ल}}$ J. R. Geigy S.A., Basle.

Frohlich, E. D., Schnaper, H. W., Wilson, I. M., and Freis, E. DO (1960). Hemodynamic alterations in hypertensive patients dueo to chlorthiazide. New Engl. J. Med., 262, 1261-1263.

Geisböck, F. (1905). Die Bedeutung der Blutdruckmessung für die Praxis. Dtsch. Arch. klin. Med., 83, 363-409. Hall, C. A. (1965), Gaisböck's disease: redefinition of an old syndrome
Arch. intern. Med., 116, 4-9.

Hilden, M., Leth, A., and Hilden, T. (1968). High haemoglobin values during medical treatment of hypertension. Brit. med. J., 2? 163-165.

Julius, S., Pascual, A. V., Reilly, K., and London, R. (1971). Abnor $\overrightarrow{\vec{\omega}}$ malities of plasma volume in borderline hypertension. Arch intern. Med., 127, 116-119.

Kaung, D. T., and Peterson, R. E. (1962). 'Relative polycythemia or 'pseudopolycythemia'. Arch. intern. Med., 110, 456-460. iv

Lawrence, J. H., and Berlin, N. I. (1952). Relative polycythaemia - the polycythaemia of stress. Yale J. biol. Med., 24, 498-505. iv

Leth, A. (1970). Changes in plasma and extracellular fluid volumes in patients with essential hypertension during long-term treat:웅 ment with hydrochlorothiazide. Circulation, 42, 479-485.

Lewis, S. M. (1973). International Committee for Standardization in Hematology (ICSH), Panel on Diagnostic Applications of Radioisotopes in Haematology. Standard techniques for the measurement of red-cell and plasma volume: a report. Brit.J® Haemat., 25, 795.

Russell, R. P., and Conley, C. L. (1964). Benign polycythemia Gaisböck's syndrome. Arch. intern. Med., 114, 734-740.

Smith, J. F. B., and Lucie, N. P. (1973). Alcohol-a cause of stress erythrocytosis? Lancet, 1, 637-638.

Tibblin, G., Bergentz, S. E., Bjure, J., and Wilhemsen, L. (1966) Hematocrit, plasma protein, plasma volume, and viscosity in early hypertensive disease. Amer. Heart J., 72, 165-176

Waldmann, T. A., Levin, E. H., and Baldwin, M. (1961). The assogaa tion of polycythemia with a cerebellar hemangioblastofa the production of an erythropoiesis-stimulating factor by tumor. Amer. J. Med., 31, 318-324.

Wilson, I. M., and Freis, E. D. (1959). Relationship between plasm and extracellular fluid volume depletion and the antihyper@ tensive effect of chlorothiazide. Circulation, 20, 1028-1036. 